\title{
NATURALEZA JURÍDICA Y CONTENIDO ACTUAL DE LAS SANCIONES ECONÓMICAS. EL CASO DE IRAK
}

\author{
Juan Manuel PORTILLA GÓMEZ*
}

RESUMEN: Las sanciones económicas aplicadas por el Consejo de Seguridad se han caracterizado por su inconsistencia, y el saldo de las mismas ha sido mayormente negativo. En el caso específico de Irak, el Consejo de Seguridad ha excedido sus facultades en la imposición de sanciones a dicha nación e incluso ha violado normas de carácter humanitario. Con el fin de obtener un mecanismo eficaz en esta materia, deben modificarse ciertas disposiciones de la Carta de las Naciones Unidas, relativas al uso de la fuerza, para lograr un mayor control de las acciones militares por parte de esta organización, y evitar que se repitan situaciones como las de Irak, cuya población ha sufrido consecuencias terribles.

ABSTRACT: The economic sanctions applied by the Security Council are characterized by its inconsistency, and its balance has been mostly negative. In the specific case of Iraq, the Security Council has exceeded its powers in the imposition of sanctions to that nation, and has even violated humanitarian norms. In order to obtain an effective mechanism in this matter, certain provisions related to the use of force must be modified to get a greater control of military actions by this organization and to avoid situations such as Iraq whose population has suffered terrible consequences.

RÉSUMÉ: La caractéristique des sanctions économiques qu'applique le Conseil de sécurité est leur manque de consistance, de sorte qu'elles se sont soldées surtout par des résultats négatifs. Dans le cas particulier de l'Irak, dans l'exercice de ses facultés, le Conseil de sécurité a imposé des sanctions à ce pays et a même été amené à violer des normes de type humanitaire. Afin d'obtenir un mécanisme efficace en la matière, il convient de modifier certaines dispositions de la Charte des Nations Unies relatives à l'usage de la force, de telle sorte que cette organisation ait un plus fort contrôle des actions militaires et d'éviter que se reproduisent des situations similaires à celle produite en Irak, dont la population a souffert de terribles conséquences.

* Profesor de derecho internacional de la UNAM, Campus Acatlán. 
SUMARIO: I. Introducción. II. Breve historia del uso de las sanciones. III. Las sanciones económicas en la Carta de las $\mathrm{Na}$ ciones Unidas. IV. La efectividad de las sanciones económicas. V. Las sanciones como señales. VI. El impacto humanitario de las sanciones. VII. Marco jurídico de las sanciones del Consejo de Seguridad. VIII. El uso de la fuerza como respaldo de sanciones económicas. IX. La continuación de las sanciones. X. Conclusiones.

\section{INTRODUCCIÓN}

El término sanción admite múltiples definiciones pero en el contexto de la normatividad de las Naciones Unidas tiene un significado muy específico. La Carta de las Naciones Unidas no emplea en ningún momento la palabra sanción para referirse a las medidas que deben tomarse por el Consejo de Seguridad. ${ }^{1}$ Se hace referencia a medidas concretas, incluyendo la interrupción total o parcial de las relaciones económicas y de las comunicaciones ferroviarias, marítimas, aéreas, postales, telegráficas, radioeléctricas, y otros medios de comunicación, así como la ruptura de relaciones diplomáticas, ${ }^{2}$ y la acción por aire, mar o tierra. ${ }^{3}$ De manera general, la carta sólo hace referencia a medidas necesarias para el mantenimiento de la paz y la seguridad internacionales, ${ }^{4}$ y para restaurar el orden en el ámbito internacional. ${ }^{5}$ Con la finalidad de entender cómo opera la utilización de las medidas de carácter económico, es necesario revisar el significado de sanción.

En una definición de diccionario, ${ }^{6}$ se indica el contexto ético bajo el cual una sanción es motivo de obediencia para cualquier ley moral o religiosa. ${ }^{7}$ Un concepto así tiene una connotación interesante: señala una razón para acatar voluntariamente un determinado código de conducta. Es de subrayarse su aproximación a una norma religiosa por cuanto implica que la conducta buscada tiene un valor ético que propicia su acatamiento.

1 Kochler, Hans, Ethical Aspects of Sanctions in International Law: The Practice of Sanctions Policy And Human Rights, htpp://www.embargos.de/.

2 Artículo 41 de la Carta de la ONU.

3 Ibidem, artículo 42.

4 Ibidem, preámbulo, párrafo 2; artículo 1.1; capítulo VI.

5 Ibidem, capítulo VII.

6 Chambers 20th. Century Dictionary, 1983.

7 La palabra tiene la misma raíz latina de santuario, un sitio de retiro. 
El curso de acción requerido se cumple debido al valor que representa para aquellos que lo llevan a cabo. Sin embargo, es notoria la ausencia de referencia a castigos o recompensas: la sanción es un motivo intrínseco y el comportamiento constituye una recompensa por sí mismo.

Mientras esta definición incide en la ética inherente de una forma de conducta, otras definiciones se enfocan en el aspecto coercitivo de las sanciones. De este modo, una sanción es una pena o recompensa expresamente derivada de la observancia o no de una medida legal. Asimismo, se define como una medida militar o económica tomada para persuadir a un Estado para seguir cierto curso de acción. Esto apunta hacia dos aspectos cruciales de las sanciones tal como se aplican por las Naciones Unidas: primero, las sanciones son establecidas como la aceptación por un Estado de ciertos valores o normas legales, acatados libremente o impuestos en contra su voluntad, y segundo, las sanciones están diseñadas para persuadir a los actores estatales. Quizá el aspecto menos destacado de las sanciones es que éstas pueden establecerse como una forma de recompensa y siendo así el concepto no es sólo de carácter punitivo. ${ }^{8} \mathrm{Com}$ binando estos conceptos, podemos establecer el fundamento de la sanción en la coerción a un Estado o un individuo, por medios justos o no, para seguir cierto comportamiento ante la inobservancia de una determinada norma jurídica. ${ }^{9}$ Aún y cuando el curso de acción demandado carezca de solidez ética, esto puede no ser relevante si la intención es enviar señales, por ejemplo en forma de sanciones económicas, en respuesta a actos que de suyo no sean violaciones de ninguna norma pero que son reprobados moralmente. ${ }^{10}$

Las sanciones económicas son un género específico de sanción. Una definición estándar de sanción económica señala que se trata de una medida impuesta por un Estado a otro privándolo de relaciones comerciales

8 Sin embargo, Nossal subraya que la raíz latina sanctio precisaba una pena y observa que hasta el siglo XVII se usó dicho término en un sentido punitivo. Nossal, Leyton y Brown, David (eds.), The Utility of Economic Sanctions, Londres, Croom Helm, 1987, p. 10.

9 Nossal señala el cambio de énfasis en años recientes, en el que la ilegalidad de un acto determinado no es tan importante, sino mas bien la posibilidad de alterar la conducta de un determinado actor por un sistema de recompensas o castigos, ibidem, p. 11.

10 Reisman opina que la imposición de sanciones económicas en algunas circunstancias puede verse como una opinio iuris en favor de los derechos humanos. Reisman, W. Michael, "Humanitarian Intervention and Fledging Democracies", Fordham International Law Journal, núm. 18, 1995, p. 798. 
y financieras ${ }^{11}$ con objeto de persuadirlo de conformarse a una norma o a castigarlos por violaciones al derecho internacional. ${ }^{12}$ Sin embargo, debe notarse que aunque las sanciones estén dirigidas a las naciones, impactan a los individuos restringiendo su acceso al comercio internacional. Más aún, las medidas no buscan hacer cambiar a una nación su conducta, sino convencer a sus líderes de modificar sus políticas. Por ello para los propósitos de este trabajo, entendemos como sanciones económicas a las medidas no militares utilizadas para obligar a los líderes de una nación a seguir un determinado comportamiento o imponerles un castigo por dirigir a ésta de un modo contrario al derecho internacional. ${ }^{13}$ Esta es la forma en que las sanciones económicas son vistas por el Consejo de Seguri$\operatorname{dad}^{14} \mathrm{y}$ es el concepto en el cual centraremos nuestro análisis.

\section{BREVE HISTORIA DEL USO DE LAS SANCIONES}

Aún y cuando existen referencias muy antiguas sobre el uso de las sanciones como el decreto Megarian de Pericles, de 432 a. C., en respuesta al secuestro de tres mujeres aspasianas y que desencadenó la Guerra del Peloponeso, ${ }^{15}$ no fue sino hasta el periodo entre guerras que la aplicación de sanciones se puso en boga. Los signatarios del Pacto Briand-Kellogg renunciaron al uso de la guerra como instrumento de política nacional. Por su parte, los fundadores de la Liga de las Naciones, y particularmente Woodrow Wilson, vieron en la "coerción pacífica del boycott"16 una manera de obligar a cumplir a las naciones recalcitrantes: "A nation that is boycotted is a nation that is in sight of surrender. Apply

11 Hufbauer, Schott y Elliot, Economic Sanctions Reconsidered, Washington, Institute for International Economics, 1990, p. 2.

12 Fausey, Joy K., Does the United Nations Use of Collective Sanctions to Protect Human Rights Violate Its Own Human Rights Standards?, Connecticut Journal of International Law, núm. 10, 1994, p. 196.

13 Idem.

14 Aunque Kofi Annan niega que las sanciones económicas estén diseñadas para castigar a las naciones, el examen de los hechos en Irak deja muy pocas dudas de que han sido utilizadas para estos fines. Supplement to an Agenda For Peace, A/50/60-S/1995/1 (1995).

15 Es oportuno observar que los magarianos estaban condenados a morir de hambre poco a poco. Las sanciones fueron ineficaces ya que no consiguieron la devolución de las mujeres secuestradas y no pudo evitarse recurrir a la guerra. "An Early Example of the Ineffectiveness of Blanket Measures", Hufbauer et al., op. cit., nota 11, p. 4.

16 Gordon, Joy, "When Economic Sanctions Become Weapons of Mass Distruction", www.conconlicts.ssrc.org/iraq/gordon. 
this economic, peaceful, salint, deadly remedy and there will be no need for force. It is a terrible remedy: It does not cost a life outside the nation boycotted, but it brings a pressure upon the nation which, in my judgement, no nation could resist". ${ }^{17}$

Así el artículo XVI del Pacto de la Liga de las Naciones obligaba a los Estados miembros a someter a cualquier Estado que violara las estrictas limitaciones sobre uso de la fuerza a diversas medidas, aunque no les llamó sanciones: "All other Members of the League... hereby undertake to subject [the guilty State] to the severance of all trade or financial arrangements, the prohibition of all intercourse between their nationals and the national of the Covenant-breaking State and the nationals of any other State".

Bajo los términos del pacto, cualquier Estado que violara las normas relativas al uso de la fuerza era ipso facto acusado de haber cometido un delito y los demás Estados miembros eran requeridos a emprender acciones en su contra. ${ }^{18}$ No existía ninguna deliberación sobre las medidas y las sanciones debían aplicarse de inmediato. Más aún, estaba previsto en el artículo XVI que podría usarse la fuerza para respaldar estas medidas y asegurar un mayor cumplimiento de los términos del pacto. Sin embargo, fue quizá por este requisito de inmediatez que el pacto se derrumbó ya que no había un cuerpo central para juzgar las acciones de los Estados. ${ }^{19}$

Sin duda, esta deficiencia en el sistema de la liga impidió que se lograran avances significativos en la aplicación de sanciones económicas. Aunque se consiguieron logros menores contra Yugoslavia en $1921^{20}$ y Grecia en $1925 ;{ }^{21}$ en 1931, la liga no intervino tras la invasión japonesa de Manchuria, ${ }^{22}$ y luego, en 1935, actuó demasiado tarde cuando Italia invadió Abisinia. ${ }^{23}$ A pesar de la percepción general de que las sanciones económicas no habían cumplido con su objetivos", ${ }^{24}$ se les concedió a

17 Padover, Saul K. (ed.), Wilson's Ideals, Washington, American Council on Public Affairs, 1942. p. 108; cfr. Gibson, Susan S., "International Economic Sanctions: The Importance of Government Structures", Emory International Law Review, núm. 13, 1999, p. 169.

18 Nossal et al., op. cit., nota 8, p. 12.

19 Ibidem, p. 14.

20 Hufbauer et al., op. cit., nota 11, pp. 124-127.

21 Ibidem, pp. 128-131.

22 Gibson, op. cit., nota 17, p. 169.

23 Hufbauer et al., op. cit., nota 11, pp. 142-149.

24 Idem. 
éstas un papel central en los procedimientos de la Carta de las Naciones Unidas. Por ello, a la luz de los antecedentes en esta materia y del equívoco vaticinio de Wilson de que no habría más conflictos al aplicarse un régimen de sanciones, resulta incongruente la supremacía concedida a las sanciones económicas en el capítulo VII de la carta.

\section{LAS SANCIONES ECONÓMICAS EN LA CARTA DE LAS NACIONES UNIDAS}

Hay varios factores para explicar la continuidad de las sanciones económicas en la Carta de las Naciones Unidas. Primero, el reconocimiento de que ciertas medidas económicas de los aliados, aunque tardías, contribuyeron a la derrota definitiva de las potencias del Eje. ${ }^{25}$ Esto nos lleva al segundo punto, consistente en que el sistema de las Naciones Unidas fue estructurado para superar las deficiencias del sistema anterior. ${ }^{26}$ Es en este sentid, que se le confirió al Consejo de Seguridad una mayor responsabilidad que la otorgada al consejo bajo el pacto. Al diseñar los procedimientos del capítulo VII se puso especial énfasis en facultar al Consejo de Seguridad para responder adecuadamente frente a situaciones concretas, a diferencia del régimen de sanciones obligatorias bajo el sistema anterior. ${ }^{27}$ Más aún, la delegación de poderes a una autoridad central busca evitar la necesidad de pronunciarse individualmente sobre la conducta de los Estados permitiendo un mayor margen de acción.

Asimismo, se dieron amplias facultades al Consejo de Seguridad para actuar antes de que los Estados puedan amenazar el orden internacional con una agresión. Bajo el capítulo VI, se facultó al Consejo de Seguridad para investigar cualquier situación que pueda amenazar el mantenimiento de la paz y la seguridad internacionales, ya sea independientemente, ${ }^{28}$ a petición de cualquier parte en una disputa, ${ }^{29}$ o a solicitud de un tercer Estado. ${ }^{30}$ Sin una resolución dentro del capítulo VII de la carta, el Consejo de Seguridad sólo puede emitir declaraciones, mismas

25 Doxey, Margaret, Economic Sanctions and International Enforcement, London, Macmillan, 1980, pp. 12-14.

26 Nossal, op. cit., nota 8, pp. 16-18.

27 Hufbauer et al., op. cit., nota 11, p. 14.

28 Artículo 34, Carta de la ONU.

29 Ibidem, artículo 38.

30 Ibidem, artículo 35. 
que no son vinculantes para los Estados miembros. No obstante ello, la disposición del artículo 25 de que todos los Estados deben actuar de acuerdo con los principios de las Naciones Unidas significa que las recomendaciones del Consejo de Seguridad tienen un gran peso moral por cuanto representan la opinión de la autoridad central de las Naciones Unidas de lo que es contrario o no a los principios y propósitos de la organización. ${ }^{31}$ Dentro de este orden de ideas, podría argumentarse que las Naciones Unidas tienen un carácter más preventivo que correctivo. Esto explica la similitud de los umbrales de los capítulos VI y VII ya que mientras en el artículo 34 el Consejo de Seguridad tiene autoridad para investigar cualquier situación que pueda amenazar la paz y la seguridad internacionales, el artículo 39 es aplicable por amenazas a la paz y la seguridad internacionales. ${ }^{32}$ Por principio, podría argumentarse que al colocar los dos umbrales tan próximos, los redactores de la carta buscaron un sistema en el que las medidas económicas pudieran prevalecer sobre las diplomáticas, sin que hubiese un agravamiento del conflicto en cuestión. Siendo las sanciones el primer puerto de llamada una vez que la diplomacia ha fallado, las sanciones juegan un papel muy diferente al que estaba previsto en el pacto. La meta es más modesta: no se trata de castigar a un Estado agresor sino de hacerle una severa advertencia de tal modo que las sanciones económicas se ubican a medio camino entre la retórica y la fuerza militar. ${ }^{33}$ Por eso a menudo se hace referencia a éstas como medidas de "capítulo 6 y medio".

Sin embargo, esta interpretación plantea un problema mayor: considerar la relación del uso de la fuerza con el uso de medidas económicas. Los artículos 41 y 42 fueron moldeados con base en el artículo XVI del Pacto de la Liga de las Naciones, aunque para tiempos y propósitos diferentes. El umbral para la aplicación de las medidas de fuerza bajo la carta es prácticamente igual que el de la aplicación de las medidas carentes de fuerza: como mínimo una amenaza a la paz. La única diferencia es que el

31 Véase caso Namibia, Legal Consequences for States of the Continuos Presence of South Africa in Namibia (South-West Africa) Notwthstanding Security Council Resolution 276 (1970), Advisory Opinion of 21 June, 1971, International Court of Justice.

32 Cfr. Gordon, Ruth, "United Nations Intervention in Internal Conflicts: Iraq, Somalia and Beyond”, Michigan Journal of International Law, núm. 15, 1994, pp. 565 y 566.

33 Cfr. Mesa Delmonte, Luis, "Economic Sanctions, Iraq, and U. S. Foreign Policy", Transnational Law \& Contemporary Problems, núm. 11, 2001, p. 347. 
Consejo de Seguridad debe evaluar la eficacia de tales medidas antes de proceder a la autorización del uso de la fuerza bajo el artículo 42.

No hay que perder de vista que uno de los objetivos principales establecidos en la Carta de la ONU es prohibir la guerra ${ }^{34}$ y para tal efecto requiere que los Estados arreglen sus disputas pacíficamente, ${ }^{35}$ debiendo abstenerse en sus relaciones internacionales de la amenaza o el uso de la fuerza. ${ }^{36}$ La evolución de la prohibición consuetudinaria sobre el uso de la fuerza se refleja en la Declaración de las Naciones Unidas sobre las Relaciones de Amistad de 1970,37 así como en la Declaración de Manila sobre la Solución Pacífica de Controversias de 1982. ${ }^{38}$ Inclusive los usos de la fuerza permitidos, como el autorizado por el Consejo de Seguridad y el de legítima defensa, guardan una gran distancia en relación con las formas anteriores. ${ }^{39}$ Asimismo, el desarrollo paralelo experimentado por el derecho internacional humanitario ha servido para regular el uso de la fuerza en la conducción de las hostilidades. ${ }^{40}$ De este modo podemos ver como se han restringido los medios, la forma y la justificación para el uso de la fuerza a partir de la adopción de la carta. Estos desarrollos en el uso de la fuerza por los Estados se han reflejado en su utilización por los cuerpos supranacionales.

Donde se presenta un problema conceptual es en la relación que guardan las medidas coercitivas con las no coercitivas. Por una parte, la determinación del umbral para la aplicación de sanciones económicas ha sido previsto de tal modo que permite acceder a un uso temprano de la herramienta económica. Por otra parte, mientras el uso de la fuerza está altamente constreñido, el uso de instrumentos económicos no lo está. Teniendo en mente los avances que han tenido lugar en las comunicaciones y en el comercio global, el "arma económica" es ahora más potente que nunca. Por ello es válido el planteamiento de si en la actualidad los efec-

34 Steiner, Henry y Alston, Phillip, Internacional Human Rights in Context: Law, Politics, Morals, Oxford University Press, 2000, pp. 137 y 138.

35 Artículo 2.3.

36 Artículo 2.4.

37 GA Res. 2625-XXV.

38 GA Res. 37/10.

39 Frowein, A. y Simma, Bruno (eds.), The Charter of the United Nations: A Commentary, Oxford University Press, 1994, p. 677.

40 Convenios de Ginebra de 1949, además de otros tratados más específicos como los que prohíben el uso de las minas antipersonales y los tratados de no proliferación nuclear. 
tos de las sanciones económicas pueden ser, en ciertos casos, más nocivos que los de las acciones militares.

\section{LA EFECTIVIDAD DE LAS SANCIONES ECONÓMICAS}

Una cuestión recurrente en todo debate sobre las sanciones económicas es si éstas logran obtener los fines perseguidos. No tiene mayor sentido recurrir a medidas de esta magnitud a sabiendas que hay nulas o escasas posibilidades de éxito. La experimentación puede ser útil en otras áreas del conocimiento pero aquí se trata de opciones políticas con importantes repercusiones económicas y humanas. Antes de encontrar una respuesta definitiva sobre esta cuestión, es necesario aclarar el alcance y significado de los términos implicados.

Primero, es menester precisar qué se entiende por "efectivo". Una definición de diccionario señala que algo es "efectivo" si consigue producir un resultado o efecto..$^{41}$ Obviamente, lo que no indica es si hay o debe haber algún vínculo entre este resultado final y los objetivos iniciales buscados. Esta definición pasa por alto cuestiones como la existencia de objetivos claros iniciales y si éstos son legítimos. Asimismo, tampoco alude a los resultados ni a la posibilidad de prever efectos diferentes. Estos son los mayores cuestionamientos que se presentan en la evaluación de las sanciones económicas.

Es necesario ubicar a las sanciones económicas en su justa dimensión y acotar las expectativas que éstas generan. Para ello hay que reconocer que las sanciones económicas son herramientas más que políticas propiamente. ${ }^{42}$ Deben diseñarse e instrumentarse con el propósito de obtener ciertos resultados, pero sin perder de vista que son sólo medios, no fines. Por eso debemos concluir que las sanciones económicas son únicamente válidas en la medida que lo sean las políticas de las cuales se derivan. ${ }^{43}$

Aunque las sanciones económicas fueron previstas como instrumentos para aislar un país de la comunidad mundial, con el tiempo han evolucionado hacia un concepto más flexible. A nivel unilateral han sido fre-

41 Chambers Dictionary, cit., nota 6.

42 Wolcott, Kira, "Ongoing at The Carter Center: Seeking Effective Sanctions", Emory International Law Review, núm. 11, 1977, p. 360.

43 Cortright, David y López, George, The Sanctions Decade: Assesing United Nations Strategies in the 1990s, Boulder, Lynne Rienner Publishers, 2000, p. 223. 
cuentemente utilizadas como herramientas de posicionamiento político ${ }^{44}$ y se ha recurrido a ellas tanto para fines menores: influir sobre políticas comerciales, como para propósitos mayores: desestabilizar regímenes. ${ }^{45}$ Antes de 1990, fueron usadas multilateralmente con alguna indulgencia con el objetivo de mostrar desaprobación de cierto régimen o para presionar en favor de la democracia y los derechos humanos en un país determinado. Después de 1990 sus objetivos se han vuelto más diversos: se han dirigido para revertir un curso de acción; ${ }^{46}$ descontinuar una política que agravia a la comunidad internacional; ${ }^{47}$ hacer cumplir con altos al fuego y resoluciones del Consejo de Seguridad, ${ }^{48}$ así como para remover del mercado ciertas productos. ${ }^{49}$ En función de ello, los partidarios de las sanciones pueden decir que las múltiples formas que pueden adoptar favorecen su adaptabilidad y los cínicos, peor aún, pueden señalar que cada vez que dejan de producirse resultados en un área, se ponen a trabajar en otra.

Es difícil que el éxito de las sanciones se obtenga solamente a través de medidas económicas, y la experiencia demuestra que las mayores concesiones se han logrado mediante la amenaza o empleo de la fuerza. Doxey resume este punto afirmando que las propiedades coercitivas de las sanciones son limitadas y que a menudo su impacto puede verse reducido. ${ }^{50}$ Esto nos lleva ipso facto a cuestionar si las medidas económicas son siempre adecuadas para lograr el nivel de resultados buscados, particularmente cuando son aplicadas de conformidad con el capítulo VII de la Carta de las Naciones Unidas.

44 Estados Unidos de América ocupa el primer lugar en la imposición de sanciones unilaterales. Éstas han sido su instrumento favorito después de la Segunda Guerra Mundial, cuando el mundo se hizo dependiente de su ayuda para lograr su recuperación económica. En la medida en que esta ayuda ha declinado, ha disminuido el uso del instrumento. Gibson, op. cit., nota 17, pp. 173-174.

45 Caso 60-1, US v. Dominican Republic (Trujillo) 1960. Hufbauer et al., op. cit., nota 11, pp. 346-359.

46 Tras la invasión de Irak a Kuwait.

47 Como se usaron en contra de Milosevic en respuesta a sus acciones de limpieza étnica, Cortright, David y López, George (eds.), Smart Sanctions: Targeting Economic Statecraft, Oxford, Rowman y Littlefield Publishers, 2002, pp. 19-21.

48 Por ejemplo, en contra de Irak en la Resolución 687.

49 Como en el caso de los "diamantes de sangre" de Angola y Sierra Leona 1989-2000, Cortright y López, op. cit., nota 47, pp. 11 y 12.

50 Doxey, op. cit., nota 25, p. 131. Se estima que de 40 casos registrados como exitosos en el estudio de Hufbauer, sólo puede decirse que cinco se ubican en esa categoría, y los restantes fueron resueltos mediante el uso directo o indirecto de la fuerza, Pope, citado en Gibson, op. cit., nota 17, p. 177. 


\section{LAS SANCIONES COMO SEÑALES}

La cuestión de las "señales" tiene dos ángulos. Por un lado, las sanciones pueden usarse por gobiernos ansiosos en mostrar que están haciendo algo acerca de una situación en particular. En buena medida esto es causado por el llamado "efecto CNN" — grandes segmentos de información transmitidos a los hogares de la gente cuya indignación moral exige una respuesta de igual envergadura- $-{ }^{51}$ Así el rápido recurso a las sanciones responde a la expectativa de ocuparse de una cuestión sin necesidad de asumir un compromiso total..$^{52} \mathrm{El}$ riesgo es que al actuar con premura se estructuren esquemas inadecuados. A pesar de ello, las decisiones precipitadas usualmente no son reconsideradas y por lo tanto no son retiradas luego de comprobar que son inapropiadas. Más aún, toda vez que las sanciones son impuestas para mostrar desaprobación, su remoción sin un logro sustancial de sus objetivos podría interpretarse como una señal de debilidad. Asimismo, la imposición arbitraria de sanciones con la finalidad de complacer a actores domésticos, más que resolver una crisis internacional significa abusar del instrumento y debilitar la utilidad de las sanciones en el largo plazo.

El segundo aspecto de "señales" se refiere al mensaje moral enviado al Estado destinatario y al mundo en general. En su calidad de herramientas de política exterior, esto hacer ver a las sanciones más simbólicas que estratégicas. ${ }^{53}$ Bajo esta perspectiva, el hecho de que una política de sanciones no logre todo lo que se propuso, no significa que haya fracasado. ${ }^{54}$ Las sanciones nunca son cien por ciento efectivas; su "éxito" debe verse en relación con el cuadro completo. Sin embargo, afirmar que el éxito de la política de sanciones está implícito en su propia existencia es ir demasiado lejos. Aunque hay que reconocer que el esquema tendría algún éxito si el régimen se impusiera, al menos en parte, para exigir la observancia de una norma moral o legal, y en el curso de la campaña un creciente número de Estados aceptara la validez del mismo.

51 Ibidem, pp. 184 y 185.

52 Por supuesto, este fenómeno no es nuevo - Hufbauer et al., notan que las sanciones impuestas a Italia en 1935 "llegaron muy tarde para salvar a Abisinia... pero justo a tiempo para salvar al gobierno británico"-. Hufbauer et al., op. cit., nota 11, p. 3.

53 Gibson, op. cit., nota 17, p. 185.

54 Cfr. ibidem, p. 184. 
El aspecto final de las señales radica en la decisión de actuar. ¿Se transmite al Estado destinatario el mensaje de que su comportamiento es reprobable y que pueden emprenderse nuevas acciones en su contra? ¿O sólo se le comunica que aunque sus políticas son inaceptables no están preparados para respaldar por la fuerza su desaprobación? En la medida en que el Estado destinatario se convenza de la decisión de que actuarán en contra suya de no modificar sus políticas, éste cederá y la sanción será "exitosa". ${ }^{55}$ De otro modo, proseguirá con su conducta y las naciones sancionadoras tendrán dos opciones: respaldar su reclamo por la fuerza o retroceder. El problema de ver a las sanciones únicamente como un indicativo de la intención de usar la fuerza es que se parte de la idea de que su alcance es limitado. Sin embargo, esta apreciación tiende a ignorar el potencial de las sanciones si se aplican correctamente.

\section{EL IMPACTO HUMANITARIO DE LAS SANCIONES}

Tras el fin de la Guerra Fría ha habido una reactivación de las sanciones económicas como instrumento de política internacional y los estudiosos del tema han tenido oportunidad de analizar este fenómeno a través de los diferentes escenarios donde se han presentado. ${ }^{56}$ En la mayor parte de los trabajos se han señalado los efectos colaterales de las sanciones basándose en la teoría tradicional, la cual indica que para que funcionen éstas deben tener un efecto tangible y significativo sobre la población del Estado destinatario. ${ }^{57}$ Sólo cuando la situación adquiere proporciones desastrosas para la población, los líderes de esas naciones reaccionan y buscan modificar su conducta. Para constatar la magnitud que pueden alcanzar los daños colaterales, basta observar el ejemplo de Irak en donde una gran cantidad de niños han fallecido como consecuencia directa de las sanciones. ${ }^{58}$

55 Este escenario ha descrito a las sanciones con la mayor eficacia. Sin embargo, ignora las situaciones donde la herramienta trabaja mejor: cuando la mera amenaza de una sanción propicia que los Estados modifiquen su comportamiento. Cfr. Doxey, op. cit., nota 25, p. 106.

56 A partir de 1990, el interés por las sanciones generó una verdadera "industria" de escritos académicos sobre la materia. Wolcott, op. cit., nota 42, p. 364.

57 Nótese que aún el idealista Woodrow Wilson sabía que se perderían vidas como resultado de las sanciones, cuando declaró que "no cobraría vidas fuera de la nación destinataria". Padover et al., nota 17, p. 50 .

58 Las estimaciones numéricas varían. Pope utiliza la cifra de 567 mil en 1999; un informe de UNICEF del mismo año presenta una cifra de aproximadamente 500 mil. Denis Halliday, 
Un enfoque común de los que han estudiado esta cuestión consiste en responsabilizar por los daños causados al régimen destinatario sin considerar a quienes imponen las sanciones. Así, en el caso de Irak, afirman que los daños no han sido provocados por las sanciones de las Naciones Unidas sino por la negativa de Saddam Hussein de cumplir con las demandas del Consejo de Seguridad. Se argumenta que si éste hubiese respondido de modo diferente, las sanciones habrían sido levantadas en beneficio de la población. Este enfoque está basado en que la importancia de los fines justifica cualquier efecto negativo sobre la utilización de los medios para conseguirlos. En ese mismo orden de ideas, si el objetivo tiene un soporte moral como el que supone la remoción de una amenaza regional o mundial por parte de un régimen hostil, la elección de los medios para lograrlo está fuera de todo debate. Este punto de vista es particularmente expresado por los medios derechistas y neoconservadores ${ }^{59}$ cuya satanización de Saddam Hussein ${ }^{60}$ ha servido para afirmar que el sufrimiento de la nación iraquí ha sido resultado de sus políticas y en modo alguno de las sanciones aplicadas. ${ }^{61}$

Una variación de este enfoque radica en afirmar que aunque las sanciones causen daño, todo efecto sobre la población civil se deriva de la habilidad de la elite gobernante para transferir el sufrimiento hacia los sectores más vulnerables de la sociedad. Si bien esto pareciera una visión más racional, no podemos soslayar el hecho de que el daño causado proviene prima facie de la imposición de sanciones. Sin embargo, no podemos considerar a las acciones de auto protección del régimen destinatario como constitutivas de un "nuevo acto" que releve moralmente a los sujetos sancionadores. El que una elite gobernante se las arregle para trasladar los efectos de las sanciones a los sectores más vulnerables de la sociedad no puede constituir una validación de dicha política sino, por el contrario, demuestra lo inapropiado de las sanciones impuestas.

entrevistado en 1999, fijó una cantidad tres veces mayor que esa, coincidente con la cifra referida por Bisharat en 2001.

59 Lobe, Jim, "What is a neo-conservative anyway?", Asia Times Online, 13 August 2003.

60 Abunimah, Ali y Masri, Rania, "The Media's Deadly Spin on Iraq", en Arnove (ed.), Iraq Under Siege, pp. 101-119.

61 Véase "Q\&A" with Jim Clancy, CNN International, 13 de agosto de 2003, An interview with James Rubin; "I think the disastrous situation in Iraq is a result of a misrule of Saddam Hussein: Some of that involved making decisions for his country that caused the international community to impose penalties, just a way a criminal gets a sentence, a fine, a large fine that criminals family suffered. The family of Irak suffered from the decisions of SH when sanctions were imposed". 
Un enfoque alternativo consiste en ver a las acciones del Consejo de Seguridad a través de la perspectiva de los acuerdos internacionales y la normatividad de derechos humanos. Esta situación es particularmente pertinente cuando las sanciones en cuestión son impuestas y controladas por las Naciones Unidas, bajo cuyos auspicios se han dado los mayores avances en la protección de los derechos humanos. Algunos estudios se han enfocado por esto en la Carta de las Naciones Unidas y en la Declaración Universal de Derechos Humanos con objeto de analizar si las sanciones continuadas han violado los propósitos y principios de la propia organización. ${ }^{62}$ Otros se han enfocado en instrumentos específicos como la Convención sobre Derechos del Niño ${ }^{63}$ o la Declaración sobre el Derecho al Desarrollo ${ }^{64}$ para censurar la política de las Naciones Unidas en estos casos. Las más recientes y fuertes críticas se han enfocado en el crimen de genocidio y en su posible responsabilidad conforme a los términos de la Convención sobre la Prevención del Crimen de Genocidio. ${ }^{65}$ De acuerdo con esto, en el caso de Irak podemos estar frente a un caso en que las Naciones Unidas han actuado en contravención de su acuerdo constitutivo y de otros instrumentos internacionales.

Una conclusión del episodio iraquí es que el régimen de sanciones cuyo blanco es la totalidad de la población no hace más que incrementar sus padecimientos y tiene escasas posibilidades de lograr sus objetivos. ${ }^{66}$ Para revertir esta situación, algunos han buscado que individuos y organizaciones sean los blancos específicos de las sanciones. ${ }^{67}$ Dentro de esta

62 Kochler, Hans, "Unsactioned Suffering: A Human Rights Assesment of United Nations Sanctions on Irak", Center for Economic and Social Rights, 1996, http://www.cesr.org/text\%20 files/sanct.PDF.

63 Kozal,Peggy, "Is the Continued Use of Sanctions As Implemented Against Iraq A Violation of Internacional Human Rights", Denver Journal of International Law and Politics, núm. 28, 2000, pp. 396-399.

64 Kochler, Hans (ed.), "Economic Sanctions and Development", Internacional Progress Organization, Studies in Internacional Relations, vol. XXIII, Viena, 1997, http://www.i-p-o.org/sanc pap.ht.

65 Bisharat, George E., "Sanctions as Genocide", 11 Transnational Law \& Contemporary Problems, núm. 379, 2001; cfr. Gordon, Joy, "When Intent Makes All The Difference: Economic Sanctions on Iraq And The Accusation Of Genocide", Yale Human Rights Law Journal, núm. 5, 2002. p. 57.

66 Gibson, op. cit., nota 17, p. 181.

67 Nótese que en el 2002, el Consejo de Seguridad votó para intentar "sanciones inteligentes" en contra de Irak. Sin embargo, no levantaron al mismo tiempo las sanciones "duras" que venía aplicando. Falk observa que el cambio a sanciones "inteligentes" fue de corta vida. Falk, Richard "Iraq, the United States, and internacional Law: Beyond the Sanctions", http://www.trasnational. org/forum/forum/meet/2000/Falk_IraqUSInternatLaw.html. 
línea de pensamiento, destacan las conferencias internacionales iniciadas en Interlaken, en 1998, ${ }^{68}$ y continuadas en otras ciudades. ${ }^{69}$

Esta búsqueda se ha centrado principalmente en tratar de definir sus propósitos ${ }^{70}$ y el proceso de Interlaken se centró en "fortalecer la efectividad de las sanciones financieras de las Naciones Unidas y reducir los daños colaterales indeseados sobre la población civil y terceros países". ${ }^{71}$ Los instrumentos considerados son medidas tales como sanciones financieras, boicot de productos específicos, restricciones de viaje y embargos de armas. ${ }^{72} \mathrm{Si}$ bien tales discusiones representan un progreso significativo por cuanto implican nuevos métodos de evaluación y diseño, adolecen del problema común de todas las sanciones: la definición de "éxito".

\section{MARCO JURÍDICO DE LAS SANCIONES DEL CONSEJO DE SEGURIDAD}

La cuestión de la imposición de sanciones plantea varios puntos fundamentales acerca del papel de las Naciones Unidas en el "nuevo orden mundial". ${ }^{73}$ A partir de 1990, su posición en torno a los acontecimientos en Irak ha propiciado que muchos cuestionen la imparcialidad de la organización y a preguntarse si permanece fiel a sus propios valores. Por supuesto, la cuestión de las sanciones no se da de manera aislada. Cuestiones como la precisión de la base legal de las varias ofensivas contra Irak y el aparente desapego a principios largamente establecidos de derecho humanitario durante estas campañas, se han combinado para cuestionar el papel de las Naciones Unidas como guardián supremo de los derechos

68 Véase http://www.smartsanctions.ch/.

69 Véase $h t t p: / / w w w . u n . o r g / s c / c o m m i t t e e s /$ sanctions/iniciatives.htm para vínculos de informes sobre estos debates.

70 Cortright y López, op. cit., nota 47, p. 1.

71 Jeker, R., Chairman's Conclusions, http://www.smartsanctions.ch/Papers/1Conclusions.pdf.

72 Cortright y López, op. cit., nota 47, p. 3.

73 George Bush, padre, se refirió a la existencia de un "nuevo orden mundial" en 1990, en un discurso ante el congreso respecto a las expectativas del nuevo contexto mundial. La frase fue inicialmente acuñada para describir el escenario que siguió al colapso de la Unión Soviética, que dio fin al sistema bipolar en que las superpotencias habían emergido para dominar las relaciones internacionales durante la llamada Guerra Fría. Aunque de inicio se pensaba que habría una era de mayor estabilidad y justicia global, rápidamente se hizo evidente que significaba nada menos que el dominio de Estados Unidos de América en los asuntos mundiales. 
humanos. ${ }^{74}$ Sin embargo, el régimen de sanciones como parte de un todo es útil en el examen de la legitimidad de las acciones de las Naciones Unidas. Dentro de este orden de ideas, no se descarta que por llevar a cabo acciones cuestionables, la propia ONU haya sido blanco de ataques terribles como el perpetrado contra sus instalaciones en Bagdad en agosto de 2003.

Nuestro punto de partida es la falta de claridad respecto al carácter legal de las sanciones de las Naciones Unidas. El capítulo VII de la carta expresamente permite ciertos cursos de acción como respuesta a las amenazas a la paz, riesgos a la misma, o actos de agresión. Sin embargo, usar este mecanismo como un cheque en blanco para imponer, por casi tres décadas, sanciones a Irak constituye un exceso. La relación entre los capítulos VI, referente a la solución pacífica de controversias y el VII, referente al uso de la fuerza, es una cuestión que amerita una mayor consideración. En el núcleo del debate está la tensión entre los dos principios fundamentales de las Naciones Unidas: por una parte, actuar como garante de la paz y la seguridad internacionales (artículo 1.1) mientras por el otro, regular la prohibición del uso de la fuerza (artículo 2.4) ¿Cómo conciliar estos dos principios, cuándo las medidas no coercitivas pueden tener un mayor impacto sobre la paz y la seguridad que la propia guerra?

\section{Propósitos y principios de la $O N U$}

Entre los propósitos y principios de las Naciones Unidas encontramos los siguientes: promover la igualdad de derechos de los pueblos de todas las naciones; fomentar el progreso social y reafirmar la fe en la dignidad humana y el valor de la persona humana. Sin embargo, todo lo anterior queda en segundo plano ante el objetivo principal de la organización: el mantenimiento de la paz y la seguridad internacionales. ${ }^{75}$ Por eso el preámbulo inicia señalando la determinación de "preservar a las gene-

74 Weston, Burns H., "The Gulf Crisis in International and Foreign Relations Law, Continued: Security Council resolution 678 and Persian Gulf Decisition Making:Precarious Legitimacy", American Journal of International Law, núm. 85, 1991, pp. 528-532. Sobre la necesidad de la ONU de observar las reglas del derecho internacional humanitario, véase Glick, Richard D., "Lip Service to the Laws of War: Humanitarian Law and United Nations Armed Forces", Michigan International Law, núm. 17, 1995, p. 53.

75 Steiner y Alston observan que en esta cuestión, la carta se basa en los juicios de Nuremberg, en los cuales se estableció que planear o llevar a cabo una guerra de agresión, o una guerra en violación de tratados internacionales, constituye un crimen. Steiner y Alston, op. cit., nota 34, pp. 115 y 116. 
raciones venideras del flagelo de la guerra que dos veces durante nuestra vida ha inflingido a la humanidad sufrimientos indecibles".

No obstante que la ONU, como toda organización social, ha tenido que adaptarse a los nuevos tiempos y ha menudo se ha conducido en inéditas direcciones, su objetivo prioritario no ha variado y éste continúa siendo el núcleo duro de la estructura de la organización tal como lo establece claramente el artículo 1.1.76 Para cerrar la pinza en torno a esta cuestión, el artículo 2.4 obliga a todos los Estados miembros a "abstenerse en sus relaciones internacionales de la amenaza o uso de la fuerza en contra de la integridad territorial o la independencia política de cualquier Estado".

\section{Capítulo VI. Solución pacífica de controversias}

El artículo 33 del capítulo VI indica los diversos medios disponibles para la solución pacífica de cualquier controversia que "pueda poner en peligro el mantenimiento de la paz y la seguridad internacionales". Entre estos destacan la negociación, la mediación, el arbitraje y el arreglo judicial como vías de resolver las disputas entre los Estados, aunque el propio artículo 33 faculta al Consejo de Seguridad para investigar cualquier situación o posible desacuerdo. En este sentido, el Consejo de Seguridad tiene el poder específico para recomendar cursos de acción a las partes, ${ }^{77}$ entre los cuales se encuentra la opción de recurrir a la Corte Internacional de Justicia en la búsqueda de soluciones a las controversias de carácter legal. El énfasis en este capítulo es si la prevención y las propias Naciones Unidas, a través del Consejo de Seguridad, deben intervenir frente a cualquier cuestión que pueda representar una amenaza a la paz y la seguridad internacionales.

A pesar de las obvias ventajas del esquema del capítulo VI, la prohibición de intervenir en los asuntos internos de los Estados, tal como lo preceptúa el artículo 2.7, se pone en entredicho cuando en ocasión de medidas recomendadas por el Consejo de Seguridad se requieren acciones por parte de un Estado miembro que ha violado dicha prohibición. El que la soberanía de los Estados sea una limitante para que entren en operación los medios de solución de controversias debilita sobremanera la

76 Fausey también indica que es el único propósito de la carta que requiere el Consejo de Seguridad para actuar, Fausey, op. cit., nota 12, p. 205.

77 Artículo 36. 
capacidad de tales recomendaciones. Por ello, las medidas derivadas del capítulo VI pueden tener un efecto limitado sobre las políticas domésticas de un Estado precisamente por carecer de efectos coercitivos.

En caso de requerirse de acciones coercitivas, el Consejo de Seguridad deberá proceder conforme a lo estipulado en el capítulo VII de la carta.

\section{Capítulo VII. Acción en caso de amenazas a la paz, quebrantamientos de la paz o actos de agresión}

Si bien el contenido de la Carta de la ONU está dirigido especialmente hacia la proscripción de la fuerza como medio de solución de controversias, de igual modo establece situaciones en las que es permisible el uso de la fuerza: cuando se autoriza por el Consejo de Seguridad en respuesta a amenazas a la paz y la seguridad, ${ }^{78}$ o en legítima defensa. ${ }^{79} \mathrm{Si}$ bien la autoridad para emplear la fuerza constituye la parte esencial del capítulo VII, no se descarta del todo el recurso a la solución pacífica de controversias. Así, el artículo 39 faculta al Consejo de Seguridad a formular una "recomendación" bajo el capítulo VII, misma que difiere sustancialmente de las medidas previstas en los otros artículos de dicho capítulo. ${ }^{80}$ Por su parte, el artículo 40 permite al Consejo de Seguridad hacer un llamado a las partes en disputa a tomar medidas provisionales

78 Artículos 39, 41 y 42.

79 Artículo 51.

80 Frowein señala que aunque una interpretación textual del artículo 39 permite dos cursos de acción —una recomendación o una decisión para tomar medidas posteriores - a menudo se asume que los dos cursos de acción son análogos y así esa "recomendación" bajo este artículo puede basar su acción en los artículos 41 y 42 . El problema con este enfoque es que las recomendaciones del Consejo de Seguridad no son obligatorias para el destinatario. Pueden también hacerse bajo los artículos 34 y 37 del capítulo VI de la carta, la cual no da lugar a una autoridad concomitante para respaldar por la fuerza acciones recomendadas. Así, si el Consejo de Seguridad emite una recomendación acerca de una serie de acontecimientos, sin referencia a un capítulo o artículo específicos de la carta (véase la Resolución 731 del Consejo de Seguridad sobre los libios sospechosos de organizar el atentado de Lockerbie). Reisman observa que no quedó claro si la resolución fue adpoptada de conformidad con el capítulo VI, o como una recomendación no obligatoria bajo el artículo 39 del capítulo VII. Reisman, op. cit., nota 10, p. 879) y que entonces no hay, prima facie, una base legal para su actuación. Por esto, sin una referencia explícita a los artículos 41 o 42, las acciones tomadas por el Consejo de Seguridad pueden ser ultra vires. Considerando lo delicado de estas cuestiones, es imperativo que todos los actos de fuerza que emanan de la ONU estén basados en el derecho internacional. Cualquier confusión o falta de claridad en esta materia se refleja necesariamente en su papel como guardián del orden legal internacional. Frowein, op. cit., nota 39, pp. 614 y 615. 
con objeto de prevenir el agravamiento de la situación. Al respecto, el artículo 41 determina la forma en que el Consejo de Seguridad deberá decidir sobre la aplicación de medidas que no impliquen el uso de la fuerza, siendo esto una condición preliminar a la aplicación de la fuerza. Sólo si dichas medidas resultan inadecuadas para mantener o restaurar la paz y la seguridad internacionales, deberán emprenderse acciones que implican el uso de la fuerza. De este modo, el propio capítulo VII establece condiciones previas a la autorización del empleo de la fuerza.

\section{La importancia de una "determinación" conforme al artículo 39}

La decisión de recurrir al capítulo VII no debe tomarse a la ligera en virtud de que da lugar a las más enérgicas y rigurosas acciones que la ONU pueda emprender. Así se decidió por los redactores de la Carta de San Francisco cuando desde los trabajos preparatorios buscaron otorgar al Consejo de Seguridad tanta discrecionalidad como fuera posible dada la importancia concedida al principal objetivo de las Naciones Unidas: el mantenimiento de la paz y la seguridad internacionales. ${ }^{81}$ Para tal efecto, el Consejo de Seguridad puede decidir llevar a cabo una determinación bajo el artículo 39 basándose, al menos, en una amenaza a la paz internacional. El fundamento más sustantivo para el uso de las atribuciones que le confiere el capítulo VII se deriva del quebrantamiento de la paz y la comisión de actos de agresión. Sin embargo, esta última rara vez ha sido invocada ${ }^{82}$ quizá para evitar que disminuyan las posibilidades de que un Estado recalcitrante cambie su comportamiento, sabiéndose ya responsable del crimen de agresión. ${ }^{83}$ Igualmente escasa y errática ha sido la referencia a un quebrantamiento a la paz. ${ }^{84}$ Así es como en la gran mayoría de los casos las medidas del capítulo VII han sido determinadas bajo la categoría de una amenaza a la paz.

En virtud de las distintas determinaciones que pueden efectuarse por vía del capítulo VI o VII, según proceda, hay considerables diferencias entre lo que puede ser autorizado por uno y otro procedimientos. Confor-

81 Ibidem, p. 605.

82 No se hizo un cargo de "agresión" ni siquiera tras la invasión de Irak a Kuwait en 1990, a pesar de que la mayoría de los analistas coincidían en que constituía una clara situación de agresión.

83 Schachter, Oscar, "United Nations Law in the Gulf Conflict", American Journal of International Law, núm. 85, 1991, pp. 452 y 453.

84 Por ejemplo, la cuestión de Namibia fue calificada como un quebrantamiento de la paz cuando en realidad éste había sido un problema de larga existencia. Frowein, op. cit., nota 39, 609. 
me al primero de ellos, los Estados son susceptibles de investigación y el Consejo de Seguridad puede recomendar un curso de acción. Bajo el segundo, la escala de medidas puede oscilar desde un embargo parcial hasta una operación militar. Sin embargo, en la práctica no se han seguido criterios definidos para diferenciar una acción que ponga en peligro la paz $^{85}$ de otra que amenace la paz $^{86}$ y por ello resulta sumamente volátil la línea que separa a los capítulos VI y VII.

Cabe preguntar si la forma en que se clasifican las disputas permite a los Estados suficiente espacio de maniobra. Un Estado acusado de amenazar la paz debe estar conciente de que sus acciones son reprobadas y que se procederá en su contra. Al saber que no podrá salirse con la suya, hay más posibilidades de que un Estado responda positivamente y evite sanciones mayores. Sus acciones posteriores determinarán la escala de respuesta. Cuando una nación que amenaza la paz es acorralada puede verse empujada a asumir un comportamiento agresivo y en cambio si cuenta con un margen de acción será más propensa a negociar. Por eso cada caso debe analizarse en sus propios méritos ya que situaciones únicas requieren de respuestas igualmente únicas, y aglutinar a todas las conductas como "amenazas" en nada contribuye a justificar legalmente las sanciones.

Otra consecuencia importante al aplicar el capítulo VII concierne a los derechos del Estado recalcitrante contenidos en otros tratados. Estos ceden terreno una vez que el Consejo de Seguridad emite una determinación conforme al artículo 39, en detrimento de cualquier derecho previsto por los mismos, tanto al Estado como a su población. Esta es la interpretación de la Corte Internacional de Justicia en el caso Lockerbie. ${ }^{87}$ En este caso, el Consejo de Seguridad primero conminó a Libia entregar a los dos sospechosos acusados del atentado aéreo ${ }^{88}$ y posteriormente le impuso sanciones para obtener el cumplimiento de su requerimiento. ${ }^{89}$ Libia solicitó a la Corte Internacional de Justicia determinar que al imponerle esas sanciones, el Consejo de Seguridad incurrió en una actuación

85 Artículo 33, capítulo VI de la Carta de la ONU.

86 Artículo 39, capítulo VII de la Carta de la ONU.

87 Questions of Interpretation and Application of The 1971 Montreal Convention Arising from The Aerial Incident at Lockerbie (Lybia $v$. US), Request for The Indication of Provisional Measures, General List No. 89 (Order of April 14, International Court of Justice.

88 Resolución CS 731, 21 de enero, 1992.

89 Resolución CS 748, 31 de marzo, 1992. 
ultra vires y estaba causándole daños irreparables. Más específicamente, Libia argumentó que sus derechos bajo tratados pre-existentes, incluyendo aquellos que garantizan ciertos derechos económicos y comerciales, fueron violados por las medidas del Consejo de Seguridad..$^{90}$ En su respuesta, la corte subrayó que tanto Libia como Estados Unidos de América estaban obligados por el artículo 25 de la Carta de la ONU a observar las decisiones del Consejo de Seguridad, incluyendo la resolución 748. De conformidad con el artículo 103, el cual privilegia a la Carta de la ONU sobre cualquier otro tratado, la corte consideró que las medidas tomadas en esta instancia por el Consejo de Seguridad no podrían ser juzgadas ultra vires. Así, de acuerdo con el razonamiento de la corte, las resoluciones del Consejo de Seguridad dentro del capítulo VII relegan los derechos reconocidos por otros tratados. Por supuesto, esto no sucede con las recomendaciones del capítulo VI, las cuales no son obligatorias. Así al optar por el capítulo VII de la Carta de la ONU, el Consejo de Seguridad está facultado para dejar sin efecto derechos y obligaciones pactados en otros tratados. Sin embargo, más allá de los hechos examinados por la corte en el caso Lockerbie, los jueces consideraron factible la eventualidad de que el Consejo de Seguridad exceda sus poderes y presentarse en consecuencia una situación ultra vires.

\section{El desarrollo de criterios similares para el uso de sanciones} y para el uso de la fuerza

El uso de la fuerza está restringido en el derecho internacional mientras que el uso de las sanciones no lo está. El uso de la fuerza en combate (ius in bello) tiene su propio conjunto de normas, las cuales imponen normas mínimas a los contendientes. Esta disciplina jurídica se conoce como derecho internacional humanitario y es uno de los campos más codificados del derecho internacional.

Hemos ya comentado como las sanciones económicas pueden ser tanto o más letales que la fuerza militar. Por ello, conviene introducir cri-

90 Libia argumentó que serían vulnerados sus derechos bajo la Convención de Montreal para la Supresión de Actos Ilícitos en contra de la Seguridad de la Aviación Civil. Señalaba su apego al artículo 5.2 de dicho tratado, al procesar internamente a los dos sospechosos y que las acciones del Consejo de Seguridad dentro del capítulo VII tenían como propósito impedir la observancia de la Convención de Montreal. Por esto, solicitaron a la corte medidas precautorias para contrarrestar cualquier daño que estas medidas ilegales pudieran causar. 
terios para el uso de sanciones que reflejen los aplicados al uso de la fuerza en situaciones de conflicto armado. Así, examinaremos cuatro aspectos del derecho internacional humanitario y cómo deben reflejarse en la regulación sobre el uso de las sanciones.

\section{A. Proporcionalidad}

El principio de proporcionalidad constituye la piedra angular del derecho humanitario y consiste en que el uso de la fuerza deber ser proporcional a los fines que persigue. Dicho principio rige la legalidad tanto de las objetivos estratégicos (ius ad bellum) como de cualquier ataque que cause bajas civiles (ius in bello). ${ }^{91}$ El Protocolo Adicional I a los Convenios de Ginebra ${ }^{92}$ prohíbe cualquier ataque que pueda causar pérdida incidental de la vida o lesiones a la población civil, o dañar bienes civiles, que son excesivos respecto a la ventaja militar prevista. ${ }^{93}$ Así, por ejemplo, el ataque a un bunker es lícito sólo cuando esté siendo usado por militares, pero no lo es al saberse su utilización por civiles también. El daño colateral debe considerarse y sopesarlo con la ventaja militar a obtenerse con el ataque.

Si partimos de que el Consejo de Seguridad está obligado a cumplir con los requerimientos del derecho internacional humanitario en su actuación bajo el capítulo VII, ${ }^{4}$ luego entonces cabría ubicar a las sanciones económicas en el mismo rango que la fuerza militar. Así en el caso

91 Fischer, Horst, "The Principle of Proporcionality", en Gutman, Roy (ed.), Crimes of war: What the Public Should Know, Nueva York, W. W. Norton, 1999, http://www.crimesofwar.org/the book/book.html.

92 Protocolo Adicional a las Convenciones de Ginebra del 12 de agosto de 1949, Relativo a la Protección de las Víctimas de Conflictos Armados Internacionales, adoptado el 8 de junio de 1977, entrada en vigor el 7 de diciembre de 1979 (en adelante Protocolo Adicional I).

93 Ibidem, artículo 57.2 a).iii.

94 Glick señala que "cuando las fuerzas de las Naciones Unidas intervienen en acciones militares, la organización se convierte en parte de un conflicto armado de acuerdo con el derecho internacional humanitario y sus tropas caen bajo la definición de combatientes. Por esto, la ONU está vinculada por las mismas obligaciones que el derecho internacional humanitario preceptúa a los Estados". Glick, Richard D., "Lip Service to the Laws of War: Humanitarian Law and United Nations Armed Forces", Michigan Journal of International Law, núm. 17, 1995, p. 106. Por su parte, Gardam argumenta que "es inconcebible que con el actual énfasis en los derechos humanos y principios humanitarios, pueda verse al Consejo de Seguridad actuando en contravención de las normas sobre la conducción de los conflictos armados, las cuales se han desarrollado tan minuciosamente en muchos años por los Estados". Gardam, Judith G., "Legal Restraints On Security Council Military Enforcement Action", Michigan Journal of Internacional Law, núm. 17, 1996, p. 319. 
de Irak habría que ver si el deterioro de su economía fue proporcional al objetivo de limitar la capacidad de su armamento.

\section{B. Distinción}

Otro principio clave del derecho humanitario es el de la distinción. Las partes en un conflicto armado deben siempre distinguir entre civiles y objetos civiles por una parte, así como combatientes y blancos militares, por otra parte, debiendo dirigir sus ataques sólo contra objetivos militares. ${ }^{95}$ El artículo 3 común a los Convenios de Ginebra señala que "las personas que toman parte activa en las hostilidades... deberán en todas las circunstancias ser tratadas humanamente". Asimismo, se indica en el Protocolo Adicional I que los ataques indiscriminados están prohibidos por la imposibilidad de dirigirse contra un blanco militar específico. ${ }^{96}$

El propio secretario de las Naciones Unidas, Kofi Annan, ha reconocido que las sanciones pueden tener efectos no deseados y contravenir sus propósitos. Como parte de sus recomendaciones para mejorar las sanciones, Annan hizo un llamado para establecer mecanismos que podrían, inter alia, “(c)... medir los efectos (de las sanciones) con objeto de objeto de permitir al Consejo de Seguridad ponerse a tono con ellos con vistas a maximizar su impacto político y minimizar el daño colateral; (d)... asegurar la entrega de asistencia humanitaria a grupos vulnerables". 97

Los mayores padecimientos de los civiles por las sanciones en Irak se han derivado de la falta de acceso a alimentos y medicinas, así como por la incapacidad de reparar la infraestructura básica. Estas medidas están prohibidas por el artículo 54.2 del Protocolo Adicional I, conforme al cual "se prohíbe atacar, destruir, sustraer o inutilizar los bienes indispensables para la supervivencia de la población civil, tales como los artículos alimenticios y las zonas agrícolas que los producen, las cosechas, el ganado, las instalaciones y reservas de agua potable y las obras de riego". Considerando esto, podríamos calificar como ilegal un embargo sobre alimentos esenciales, medicinas, o cualquier otro que sea necesario

95 Protocolo Adicional I, artículo 48.

96 Ibidem, artículo 51.4.

97 Kofi Annan, op.cit., nota 14, Supplement To An Agenda For Peace, A/50/60-S/1995/1 (1995). 
para mantener o reparar la infraestructura civil. La resolución 661 y las que le siguieron incluían medidas en detrimento de tales rubros. Por ello, debe prevalecer el principio de la disponibilidad permanente de los bienes destinados primariamente al bienestar de la población civil durante la vigencia de cualquier sanción económica. El Comité para la Resolución 661, al sostener que dichos bienes podrían tener un "uso doble", aplicó la herramienta económica indiscriminadamente sin distinguir a los objetivos militares de los civiles.

\section{Armas prohibidas}

Aún y cuando la guerra no puede evitarse, se busca que los medios empleados tengan el menor impacto humano posible. Por siglos se han hecho esfuerzos para prohibir cierto tipo de $\operatorname{armas}^{98}$ o métodos de guerra que causan sufrimiento innecesario. Este concepto está muy bien resumido en el Protocolo Adicional I que señala:

1. En todo conflicto armado, el derecho de las partes en conflicto a elegir los métodos o medios en hacer la guerra no es limitado.

2. Queda prohibido el empleo de armas, proyectiles, materiales y métodos de hacer la guerra de tal índole que causen males superfluos o sufrimientos innecesarios. ${ }^{99}$

Además, existe un buen número de tratados dirigidos a la prohibición de armamentos o tácticas que causan sufrimiento indebido. Como ejemplos tenemos aquellos que incluyen la prohibición de las balas " $\mathrm{dum}$ dum", ${ }^{100}$ la prohibición del uso de gas en una situación de guerra ${ }^{101}$ y los recientes instrumentos para prohibir las minas antipersonales. ${ }^{102}$ Todos estos son ejemplos de métodos de guerra que rebasan los límites razonables de sufrimiento causado por un ser humano a otro, aún en el curso de la guerra.

98 Uno de los ejemplos más antiguos data de 1139, cuando el papa Inocencio II prohibió el uso de "flechas ardientes" en las batallas entre cristianos.

99 Protocolo Adicional I, artículo 35.

100 Declaración sobre la Prohibición del Uso de Balas Expansivas, La Haya, 29 de julio, 1899.

101 Protocolo sobre la Prohibición del Uso en la Guerra de Gases Asfixiantes, Tóxicos o Similares y de Medios Bacteriológicos, Ginebra, 17 de junio, 1925.

102 Convención sobre la Prohibición del Uso, Almacenamiento, Producción y Transferencia de Minas Antipersonales y sobre su Destrucción (Tratado de Ottawa). 
Con base en el análisis efectuado, sería posible prohibir cierto tipo de sanciones económicas. Concretamente, a la luz de la experiencia de Irak tendría sentido prohibir la imposición de embargos totales. Los efectos de tales prohibiciones draconianas han probado ser severas, impredecibles, causantes de sufrimiento innecesario y sin proporción alguna respecto a los objetivos perseguidos. Convendría descartar esta opción en el futuro y evitar que se repita lo sucedido en Irak. ${ }^{103}$

\section{Responsabilidad por violaciones al derecho internacional humanitario}

La responsabilidad derivada de acciones que violan el derecho internacional humanitario constituye una cuestión clave en la regulación actual de los conflictos bélicos. La aplicación del derecho internacional humanitario es primariamente responsabilidad de los Estados y de cualquier otra parte en un conflicto. En teoría, aquellos que violan las reglas en una situación de combate deberían ser procesados en tribunales nacionales por sus acciones. Sin embargo, dado que esto difícilmente sucede, hay una tendencia hacia internacionalizar la responsabilidad individual por graves violaciones al derecho internacional humanitario. ${ }^{104}$ Se han establecido tribunales ad hoc para tratar con crímenes cometidos en conflictos específicos como el ICTY ${ }^{105}$ y el ICTR. ${ }^{106}$ Recientemente, el Estatuto de Roma allanó el camino para el establecimiento de un tribunal internacional permanente para perseguir a quienes contraviene las leyes de guerra. ${ }^{107}$

En el marco de las Naciones Unidas, se ha buscado establecer que las decisiones del Consejo de Seguridad sean susceptibles de ser revisadas legalmente por la Corte Internacional de Justicia. Esto fue aceptado, en principio, por la propia corte en el caso Lockerbie. ${ }^{108}$ Las sanciones

103 Las Naciones Unidas no parecen haber tomado esto en consideración, y las medidas impuestas desde mediados de los noventa han sido sanciones "inteligentes".

104 Oficina de las Naciones Unidas para la Coordinacion de Asuntos Humanitarios, http://www.irinnews.org/.

105 International Criminal Tribunal for the Former Yugoslavia, http://www.un.org/icty.

106 International Criminal Tribunal for Rwanda, http://www.ictr.org.

107 Estatuto de Roma de la Corte Penal Internacional, Doc. A/CONF.183/9 del 17 de julio, 1998.

108 Questions of Interpretation And Application Of the 1971 Montreal Convention Arising From The Aerial Incident at Lockerbie (Libia v. US), request for the Indication of Provisional Mea- 
en contra de Irak violaron las normas mínimas de conducta requeridas en una situación de combate. Lo anterior fue detectado no sólo por diversas organizaciones no gubernamentales y grupos de activistas sino aún dentro de la propia ONU, aunque nada podía hacerse sin una decisión del Consejo de Seguridad para terminar con el régimen de sanciones. Ante la imposibilidad de que una instancia externa juzgue la legalidad de las acciones del Consejo de Seguridad, la Corte Internacional de Justicia pareciera ser el órgano idóneo para ello. La legalidad debiera determinarse no únicamente en términos del apego a los artículos 39 y 41, sino también respecto a las omisiones referentes a los propósitos y los principios de las Naciones Unidas. En este caso, la corte tendría que mantener un equilibrio entre la necesidad de mantener la paz y la seguridad con la necesidad de fomentar el respeto a los derechos humanos y a las libertades fundamentales de todos. ${ }^{109}$ Por supuesto, más allá de que una decisión de la corte pudiera obligar al Consejo de Seguridad, ésta serviría al menos como una indicación útil de los límites de la autoridad del Consejo de Seguridad.

\section{EL USO DE LA FUERZA COMO RESPALDO DE SANCIONES ECONÓMICAS}

La experiencia ha demostrado una falta de claridad conceptual sobre la relación de la fuerza con las sanciones económicas. Esto se manifestó en tres formas durante la crisis iraquí; primero, al autorizar la fuerza para respaldar el régimen de las sanciones en la resolución 665; segundo, al no dar a las sanciones suficiente tiempo para funcionar antes de emprender una operación militar de dudosa legalidad; y tercero al no cancelar las sanciones una vez que se había recurrido a la fuerza.

Quizá, parte del problema se debe a la forma en que los artículos 41 y 42 reflejan el artículo XVI del Pacto de la Liga de las Naciones. Bajo el pacto, las medidas coercitivas formaban explícitamente parte del régimen de sanciones. ${ }^{110}$ Sin embargo, parece no haber ninguna base para el uso de medidas militares para fiscalizar e imponer el embargo. Más aún,

110 Doxey, op. cit., nota 25, p. 43. 
se supone que en la Carta de la ONU debe observarse una estricta progresión lineal en el desarrollo de una situación. En tanto, el Consejo de Seguridad no requiere de otra declaración bajo el artículo 39 antes de que el régimen de sanciones pueda trasladarse a un ataque armado, al menos podría haberse esperado a que las sanciones hubiesen demostrado ser incapaces de lograr sus objetivos o que la situación hubiera empeorado a tal grado de prescindir de cualquier deliberación para imponer las sanciones. Si falta alguno de estos dos requisitos, el uso de la fuerza es ultra vires. A la luz de estos planteamientos, proponemos las siguientes directrices.

\section{Reformular el artículo 41 para permitir la imposición armada de los bloqueos}

Sólo puede verse como una omisión el que el artículo 41 no incluya la opción de respaldar sus términos con el músculo militar. En el caso iraquí, la resolución 665, que facultó a los Estados miembros con buques de guerra en las cercanías de Kuwait a detener buques sospechosos de burlar el bloqueo, estuvo basada sólo en la autoridad general del capítulo VII. Resulta difícil ver esa resolución basada en el artículo 42, en virtud de que éste es aplicado solamente al uso de la fuerza post sanciones y no puede ser fundamento del empleo de la fuerza durante una campaña de sanciones. ${ }^{111}$ El problema con el enfoque dado a la 665 no es que se haya hecho uso de la fuerza - la cual era necesaria para evitar la ruptura de las sanciones - El problema es acerca del desvanecimiento de la línea entre la fuerza y las sanciones, así como las limitaciones sobre ese uso de la fuerza. Las medidas coercitivas conforme al artículo 42 deben llevarse a cabo para mantener y restaurar la paz y la seguridad internacionales. Esto va más allá de prevenir violaciones a los embargos de las Naciones Unidas. El riesgo de permitir el uso de la fuerza como respaldo a las medidas del artículo 41 es que pueda parecerse a autorizar la fuerza bajo el artículo 42. Esto de ningún modo es deseable. Como ya hemos observado, la imagen de las Naciones Unidas se deteriora cuando se carece de una base legal concreta para sus acciones. El apoyo de sanciones con la fuerza es inadecuado, al no haber autorización para ello dentro de la carta. Para efectos de claridad y precisión de la autoridad de las Naciones 
Unidas, convendría reformar el artículo 41 para incluir tal disposición. Esta debería ser en el sentido de establecer que la fuerza debe sólo emplearse para dar cumplimiento a los términos del artículo 41 y para ningún otro propósito.

\section{Incrementar el control de la ONU sobre las acciones militares}

El propósito del capítulo VII es la construcción de un sistema de seguridad colectiva, centrado en las Naciones Unidas como garante de la paz mundial. Ese propósito y la realidad del Golfo Pérsico, de 1991 a 2003, han sido diametralmente opuestos. En la resolución 678, el Consejo de Seguridad votó para permitir que una coalición usara todos los medios necesarios para obtener objetivos amplios y vagos. Las Naciones Unidas no instrumentó la decisión de usar la fuerza ni la conducción de las hostilidades. De hecho, el Consejo de Seguridad no pudo dar siquiera una base firme para las acciones que tendrían lugar. Esto no ha sido más que una renuncia a su responsabilidad, ${ }^{112}$ no sólo respecto a la comunidad internacional, sino hacia el pueblo de Irak, cuyo bienestar fue ignorado por un Consejo de Seguridad manipulado por sus miembros más poderosos. Para que las Naciones Unidas tengan un mayor control deben considerarse dos elementos:

\section{A. Reconocer las limitaciones del derecho de legítima defensa}

Aunque en agosto de 1990 el Consejo de Seguridad actuó con rapidez para imponer sanciones económicas a Irak, algunos Estados no consideraron esto como una medida dirigida a restaurar la paz y la seguridad internacionales. Bajo los términos del artículo 51 de la Carta de las Naciones Unidas, cada Estado tiene "el derecho inmanente de legítima defensa, individual o colectiva, en caso de ataque armado contra un miembro de las Naciones Unidas, hasta tanto que el Consejo de Seguridad haya tomado las medidas necesarias para mantener la paz y la seguridad internacionales". Según Frowein, la inclusión del derecho a la legítima defensa acotó el concepto clásico del derecho de un Estado a responder en legítima defensa. ${ }^{113} \mathrm{El}$ hecho de la subordinación de este derecho

112 Weston, op. cit., nota 74, p. 526.

113 Este derecho clásico legitimaba un rango más amplio de acciones por parte de los Estados, muchas de éstas tan sólo consistían en buscar sus propios intereses. Al mantener el derecho de 
a la autoridad del Consejo de Seguridad debe tenerse muy presente cuando examinemos los sucesos de 1990 y 1991.

La resolución 661 es confusa porque de inicio afirma implícitamente el derecho de legítima defensa colectiva de acuerdo con el artículo 51 y luego enuncia las medidas que se llevarán a cabo para cumplir con los términos de la resolución 660. ¿Qué debemos concluir de esto? Primero, podríamos decir que eso demuestra que las medidas emprendidas bajo el artículo 41 no fueron diseñadas para restaurar la paz y la seguridad. De haber sido así, carecerían de toda base legal conforme la carta. Por razones obvias, este punto de vista es insostenible. Segundo, podríamos decir que las Naciones Unidas impusieron medidas para restaurar la paz y la seguridad, mismas que hasta en tanto fuesen efectivas no afectarían el derecho de legítima defensa. Esto es también cuestionable, ya que una estricta interpretación del artículo 51 no apoya el punto de vista de que el término "hasta", guarda alguna relación con dichas medidas de haber tenido éstas el efecto deseado. Simplemente se refiere a acciones emprendidas por la ONU con el propósito de resolver un conflicto. ${ }^{114}$ Esto nos deja con una sola posibilidad: que las Naciones Unidas optó por un curso de acción para resolver la crisis, pero ignoró cualquier otra medida que estuviere llevándose a cabo bajo el artículo 51 con el mismo fin. Sobre la base de cómo estaba conduciéndose esta campaña, esta parece ser la interpretación que más se ajusta a los hechos. De todo ello no se obtiene una conclusión conceptualmente satisfactoria. Hubiera sido preferible que la ONU señalara claramente que las medidas emprendidas bajo el artículo 41 cumplían con el "hasta" del artículo 51 y así dejar a salvo el derecho de legítima defensa. Las sanciones deben verse como auténticas medidas del Consejo de Seguridad; sólo así quienes las formulan, las aplican, y el propio Estado destinatario las tomará con la seriedad debida obligándose a su cumplimiento.

legítima defensa en la carta y someterlo a la autoridad del Consejo de Seguridad, el cual tiene como tarea el deber de actuar conforme a los principios y propósitos de la organización, sus redactores redujeron la amplitud que este derecho tenía con anterioridad. Frowein, op. cit., nota 39, pp. 665-677.

114 Rostow tiene un punto de vista opuesto. "To me, what Article 51 and Resolution 661 seem to say is... that the customary law of self-defense is not impaired in any way by the Charter but remains intact until the Council has succesfully dealt with the controversy before it". Rostow, op. cit., p. 511. 


\section{B. Incrementar el cumplimiento de los términos del artículo 42}

Como corolario de lo anterior, si la ONU desea tener un mayor control sobre el curso de las medidas conducidas bajo sus auspicios debe tener un fundamento legal para cualquier acción emprendida. En el contexto de Irak, ello habría implicado basar la resolución 678 en los términos del artículo 42. Por supuesto, el Consejo de Seguridad tendría que haber indicado expresamente que a su juicio las sanciones económicas habían probado ser ineficaces. Dicha posición habría reportado mayor credibilidad al Consejo de Seguridad; asimismo, habría tenido un efecto positivo el atribuir directamente al Consejo de Seguridad la decisión de usar la fuerza. ${ }^{115}$ De modo contrario, dicho órgano endosó el empleo de la misma a una coalición dirigida por Estados Unidos de América en nombre de Kuwait. Cualquier declaración de la ONU concerniente a la relación de esas sanciones con el uso de la fuerza habría favorecido la imagen de la organización. Igualmente, de haber encuadrado su actuación dentro del artículo 42, la ONU habría sido percibida como responsable del control sobre cualquier acción a emprenderse.

\section{Prohibición del uso de sanciones totales como medida a posteriori}

Finalmente, una lección derivada de este episodio es que las medidas económicas como las que se emplearon en contra de Irak no deben imponerse después de un conflicto armado. Desde un punto de vista estrictamente basado en la carta, no hay ninguna facultad para el uso de sanciones una vez que una situación haya sido tratada militarmente; los redactores de la carta no lo previeron, no había ninguna práctica previa en ese sentido y la lógica desaconsejaba dar dicho paso. En el caso de Irak, el Consejo de Seguridad justificó el mantenimiento de las sanciones refiriéndose a la volatilidad de la situación imperante. En la búsqueda de cumplimiento de las exigencias de desarme, las sanciones parecieron representar la mejor opción. Como ya estaba en operación un embargo bien organizado, parecía lógico continuar su aplicación y únicamente cambiar los fines para los que fue diseñado originalmente. Sin embargo, esta fue

115 Nótese que el artículo 42 señala: "Si el Consejo de Seguridad estimare que las medidas que trata el artículo 41 pueden ser inadecuadas o han demostrado serlo, podrá ejercer...". Esta es una posición activa en nombre del Consejo de Seguridad de las Naciones Unidas, opuesta al artículo 51, el cual deja la carga de la prueba al Estado atacado. 
una decisión desastrosa. Como ya se ha comentado, la destrucción militar del país propició sufrimientos sin precedentes a la población de Irak; el régimen de sanciones sólo sirvió para magnificar y exacerbar estos sufrimientos en una amplia variedad de formas.

\section{LA CONTINUACIÓN DE LAS SANCIONES}

No obstante el escaso cumplimiento de las sanciones por parte de Irak y a pesar de las reservas sobre su efectividad, aún dentro del propio Consejo de Seguridad, este órgano decidió mantenerlas. Quizá por esa razón se pensó, erróneamente, que someter a escrutinio su programa de armamentos constituía una carga menor para Irak. Las condiciones impuestas a Irak en la resolución 687 fueron no sólo onerosas sino difíciles de cumplir. La aceptación de reparaciones tendría un efecto devastador sobre la economía iraquí durante las siguientes décadas. ${ }^{116}$ Por otra parte, en una acción carente de autoridad legal explícita, la ONU resolvió la reubicación de la frontera entre Irak y Kuwait favoreciendo así a la parte victoriosa al término de un conflicto bélico. Las condiciones respecto a los arsenales químicos, bacteriológicos y balísticos excedieron a lo pactado en los tratados relevantes e impusieron requisitos más severos que los aplicados a otros países no sólo de la región sino de todo el mundo. ${ }^{117}$ Las condiciones para detectar la existencia o desarrollo de armas nucleares se tradujeron en una considerable merma de soberanía, derivada del requerimiento de tener que revelar cada detalle de los programas de armamento, actuales o futuros, a inspectores externos. Consideradas en conjunto, el efecto de dichas medidas colocaba a Irak en tal Estado de in-

116 Se estima un monto total de 276 mil millones de dólares. Cfr. Whitaker, Brian, "Iraqui Reparations Could Take a Century To Pay", The Guardian, June 16, 2000; cfr. Block, Tim, "Pariah States", And Sanctions in the Middle East: Iraq, Lybia and Sudan, Londres, Rienne Publihers, 2001, p. 192.

117 Es obvia la referencia a Israel aquí. Una seria crítica respecto al cumplimiento de la resolución 687 , por parte de quienes la establecieron, es que no emprendieron ninguna acción para lograr el objetivo del párrafo 14 de la misma: un Medio Oriente libre de armas de destrucción masiva. Tratando de desentrañar el sentido de la inclusión de dicha disposición, creemos que se buscaba hacer una advertencia a otros países en la región (excepto Israel) para que vieran lo que estaba sucediéndole a Irak por su desobediencia y pensaran dos veces antes de seguir su ejemplo. Ciertamente, cualesquiera que hayan sido las razones de su inclusión, esta disposición no ha sido aplicada por el Consejo de Seguridad fuera de Irak. Por esto, es absurdo que el Consejo de Seguridad se haya basado en una resolución sobre la agresión de un solo país para justificar acciones en torno al desarme de otros países a su alrededor. 
defensión en el que sería incapaz de repeler un acto de agresión. ${ }^{118}$ Es difícil argumentar que estos objetivos eran más modestos que los perseguidos por la resolución 661 .

Es muy difícil encontrar fundamento legal en la carta para un régimen prolongado de sanciones. Frowein califica como inédita la imposición de sanciones, presumiblemente bajo el artículo 41, para cumplir con un régimen de desarme. ${ }^{119}$ Se partió de la premisa de que a pesar del bombardeo y la ofensiva terrestre de la coalición, el régimen iraquí seguía constituyendo una amenaza a la paz y la seguridad internacionales. Dentro de esa lógica, se daba por descontado el peligro que representaba el régimen iraquí desde su invasión a Kuwait, por la idea de que sus fuerzas contaban con armamento no convencional y por su uso previo de armas químicas en contra de su propia población. ${ }^{120}$ Siendo este el caso, era correcto que el Consejo de Seguridad emprendiera algún tipo de acción bajo el capítulo VII.

Más aún, la resolución 678 había autorizado el uso de todos los medios necesarios para asegurar no sólo el desalojo iraquí de Kuwait, sino también el restablecimiento de la paz y la seguridad en la zona. Mientras que esto se refería principalmente a medidas militares, podía referirse también a otras formas de coerción bajo el capítulo VII. Así el régimen de inspección podía ser una extensión del elemento "por todos los medios posibles" de la resolución 678. Sin embargo, la resolución 687 señala expresamente que la aceptación de sus términos ponía fin a las medidas autorizadas a la coalición por la resolución 678. Por ello, el procedimiento de inspección no podía ser autorizado por esa resolución anterior.

Siendo este el caso, ¿podían considerarse tanto el régimen de inspección como la prolongación de las sanciones como medidas no coercitivas autorizadas por el artículo 41 y emprendidas contra Irak por la resolución

118 Cornell observa que al permitir a Irak retener un mínimo básico de armamento, la resolución pretendía mantener el derecho de cada nación, conforme al artículo 51, de actuar en legítima defensa para repeler un ataque. Cornell, Michael, "A Decade of Failure: The Legality and Efficacy of United Nations Actions in the Elimination of Iraqui Weapons of Mass Distruction", Connecticut Journal of International Law, núm. 16, p. 330.

119 Frowein, op. cit., nota 39, p. 628

120 Por ejemplo, contra los chiítas en Halabja en 1988. Obsérvese que la comunidad internacional no hizo nada para condenar esto, la ONU desestimó las sanciones por "prematuras". Gordon, op. cit., nota 65, p. 75. De hecho, Estados Unidos de América incrementó su ayuda económica y militar a Irak entre este suceso y la invasión a Kuwait. Chomsky, Noam, en Arnove (ed.), Iraq Under Siege, cit., nota 60, p. 66. 
661? Ciertamente puede estructurarse un régimen de inspecciones bajo el artículo 41, y las medidas económicas siguen siendo el ejemplo clásico de medidas carentes de fuerza militar. La resolución 687 evoca y reafirma las resoluciones anteriores. ${ }^{121}$ Sin embargo, el problema de basar la resolución 687 en una autoridad residual de la resolución 661 es que ésta estaba expresamente limitada a asegurar el cumplimiento iraquí del párrafo 2 de la resolución 660, o sea el retiro iraquí de Kuwait. Habiéndose logrado esto, aunque por otros medios, la resolución 661 no debía haber tenido ninguna autoridad remanente como fuente de derecho internacional. Es por esto lamentable que el Consejo de Seguridad haya optado sólo por reafirmar la resolución 661 mediante su incorporación en la propia resolución 687, extendiendo así implícitamente sus efectos más allá de las circunstancias en que fue concebida en agosto de 1990.

Como hemos observado, las sanciones están previstas en la Carta de la ONU como un paso previo a la intervención militar. Nada justifica que el Consejo de Seguridad salte del artículo 41 al 42 y luego regrese nuevamente al 41 . Esto parece contradecir los términos del artículo 42 al recurrir a medidas económicas bajo el mismo régimen una vez que la fuerza ha sido aplicada con éxito. El artículo 42 puede ser utilizado sólo si las medidas económicas son consideradas ineficaces o han probado serlo. La continuación del régimen mucho después del uso de la fuerza desmiente estos argumentos; si las sanciones se mantienen, hay una clara percepción de que son de alguna utilidad en largo plazo. Aún asumiendo que la autoridad de la resolución 678 radica en el artículo 51, no podemos ignorar el significado del término "hasta" en ese artículo. El régimen de sanciones se mantuvo a pesar de perseguir diferentes fines. Por ello, es difícil argumentar que las sanciones impuestas bajo la resolución 661 no fueron medidas emprendidas por el Consejo de Seguridad para restablecer la paz y la seguridad. En consecuencia, el derecho de legítima defensa, conforme al artículo 51, debió quedar en segundo plano desde el momento en que se aplicaron las sanciones. 


\section{CONCLUSIONES}

Las sanciones han estado presentes a largo de la existencia del derecho internacional pero no fue sino hasta el Pacto de la Liga de las Naciones que éstas fueron sistematizadas y dotadas de un régimen jurídico. La Carta de las Naciones Unidas retoma este instrumento concediéndole un sitio preferente dentro de su estructura y atribuyéndole su aplicación al Consejo de Seguridad. El saldo de la aplicación de regímenes de sanciones por parte de este órgano ha sido negativo, sobre todo en la imposición de medidas económicas, $\mathrm{y}$ ha puesto en entredicho su efectividad. La actuación del Consejo de Seguridad ha ido desde medidas banales e intrascendentes hasta severísimas medidas con un alto costo humano. Éste es el caso de Irak en el que la población civil ha padecido un sinnúmero de calamidades, destacándose la pérdida importante de vidas humanas. Los sobrevivientes han tenido que soportar casi tres décadas de aislamiento político, económico y social del resto del mundo. El único crimen del pueblo iraquí ha sido estar sometidos a un cruel e irresponsable tirano y por si esto fuera poco, han sido duramente castigados por el régimen de sanciones impulsado por Estados Unidos de América e impuesto por las Naciones Unidas. Antes de 1990, Irak era un país con una clase media educada, un fuerte tejido social y un gran sentido de dignidad. La guerra y las sanciones acabaron con esto convirtiéndolo en un país sin futuro, empobrecido y caótico. Por ello no debemos permitir que tales acciones vuelvan a repetirse bajo los auspicios de las Naciones Unidas.

En la aplicación del régimen de sanciones a Irak, el Consejo de Seguridad ha violado la propia Carta de las Naciones Unidas en forma y fondo. Por una parte, no ha seguido los procedimientos jurídicos previstos, y por otra, ha atentado contra principios fundamentales contenidos en el tratado constitutivo de la organización. Asimismo, su actuación ha vulnerado las normas del derecho internacional humanitario debido a la magnitud de los efectos nocivos sobre la población. Por ello insistimos en la conveniencia de introducir criterios similares para el uso de las sanciones y para el uso de la fuerza ya que de otro modo no se concretan los objetivos de esta importante rama del derecho internacional.

Con el fin de evitar que el Consejo de Seguridad se coloque en una situación ultra vires, habría que reformar algunas disposiciones de la Carta de las Naciones Unidas de tal modo que las acciones armadas estén 
en sintonía con el sistema de seguridad internacional y bajo un estricto control de las Naciones Unidas. Para ello, se requeriría de un reconocimiento muy puntual de las limitaciones del derecho de legítima defensa cuando éste se subordina a la autoridad del Consejo de Seguridad.

La continuación de las sanciones agregó nuevas cargas a la mermada soberanía iraquí e hizo más difíciles las condiciones de la población. Aunado a ello, el régimen de inspecciones de armamento endureció la posición del régimen de Saddam Hussein y complicó aún más la situación. La lección del episodio iraquí ha sido una de las más amargas en la historia contemporánea y ha demostrado, una vez más, la ineficacia de las sanciones económicas. Asimismo, ha confirmado la creciente sumisión de las Naciones Unidas a los intereses hegemónicos de las potencias, especialmente de Estados Unidos de América. 